\title{
Evaluation of the Quality of Educational Services of Tabriz University of Medical Sciences based on SERVQUAL Model
}

\author{
${ }^{1}$ Mohamad Ali Ghavimi, ${ }^{2}$ Mahdi Rahbar, ${ }^{3}$ Alireza Faraji Kalvanag, ${ }^{4}$ Arezo Ghoreishizadeh, ${ }^{5}$ Milad Ghanizadeh
}

\begin{abstract}
Introduction: Students in the medical field are the future authorities of the health systems in every community. In this context, the quality and efficacy of each health system is directly related to the quality of education the students in the medical field receive. In this study, we evaluated the quality of educational services by determining the gaps between students' expectations and perceptions in Tabriz University of Medical Sciences in relation to the quality of educational services.
\end{abstract}

Materials and methods: In this descriptive/analytical and cross-sectional study, the students studying in Tabriz University of Medical Sciences in 2016, who had studied for at least four semesters, were evaluated. Data were collected with the use of a two-part questionnaire. The first part consisted of questions on the demographic data of the subjects and the second part consisted of 26 questions on students' perceptions and 26 questions on their expectations in relation to the quality of educational services. Data were analyzed with descriptive and chi-squared test using Statistical Package for the Social Sciences version 21

Results: The results showed that the mean scores of the students' expectations and perceptions of the educational quality were $4.5 \pm 0.33$ and $2.9 \pm 0.7$ respectively, with a mean gap of $-1.5 \pm 0.7$.

Conclusion: The results of this study showed negative gaps in all the aspects of educational quality.

Clinical Significance: This study has no clinical significance because it is a descriptive study about quality of educational service.

Keywords: Educational service, Quality, SERVQUAL model, Students.

\footnotetext{
${ }^{1,5}$ Department of Oral and Maxillofacial Surgery, Faculty of Dentistry, Tabriz University of Medical Sciences, Tabriz, Islamic Republic of Iran

${ }^{2}$ Department of Operative and Esthetic Dentistry, Faculty of Dentistry, Tabriz University of Medical Sciences, Tabriz, Islamic Republic of Iran

${ }^{3}$ Department of Medical Laboratory Science, Faculty of Paramedical, Tabriz University of Medical Sciences, Tabriz Islamic Republic of Iran

${ }^{4}$ Department of Pediatric Dentistry, Faculty of Dentistry, Tabriz University of Medical Sciences, Tabriz, Islamic Republic of Iran

Corresponding Author: Milad Ghanizadeh, Department of Oral and Maxillofacial Surgery, Faculty of Dentistry, Tabriz University of Medical Sciences, Tabriz, Islamic Republic of Iran, Phone: +00984135440754, e-mail: milad.ghanizadeh@gmail.com
}

How to cite this article: Ghavimi MA, Rahbar M, Kalvanag AF, Ghoreishizadeh A, Ghanizadeh M. Evaluation of the Quality of Educational Services of Tabriz University of Medical Sciences based on SERVQUAL Model. World J Dent 2017;8(2):114-118.

\section{Source of support: Nil}

Conflict of interest: None

\section{INTRODUCTION}

Students in the medical field are the future authorities of the health systems in every community. In this context, the quality and efficacy of each health system is directly related to the quality of education the students in the medical field receive. ${ }^{1}$ Therefore, the majority of universities and educational institutes continually evaluate the quality of the educational services offered to students and attempt to improve the educational quality. ${ }^{2}$

Several techniques have been suggested for the evaluation of the quality of educational services. ${ }^{3-5}$ One of these techniques, i.e., widely used is the evaluation of differences between the expectations and perceptions of students as the principal clients (or recipients) of educational surfaces of the quality of educational services rendered. In this technique, to evaluate the quality of services, the client's expectations (what he/she believes it should be) and his/her perceptions (what he/ she has received) are compared and if the expectations are greater than perceptions, the quality of the services received are low based on the clients' opinion, resulting in the client's dissatisfaction. ${ }^{6,7}$ As a result, Parasuraman et al designed a tool in 1988, which is known as SERVQUAL model. ${ }^{3}$ This model is a diagnostic tool for identifying the weak and strong points of the educational services and is used to evaluate the gaps between the clients' expectations and perceptions of the quality of educational services. ${ }^{2,3}$ In fact, this tool measures and compares the expectations and perceptions of clients in five aspects, including physical or tangible, reliability, responsiveness, assurance, and empathy and if the perceptions are higher than expectations, the quality of services is high. ${ }^{2,3,7}$

Rajabi and Rajabi ${ }^{8}$ showed in a study in Shahroud University in 2014 that there were great gaps between the students' expectations and perceptions of the educational 
services offered by the university and these services did not meet the students' expectations.

A longitudinal study by Nabilou and KhorasaniZavareh $^{9}$ showed that the students in Urmia University of Medical Sciences were dissatisfied with the educational services and there were gaps in all the aspects.

A similar study in Australia showed that the students' expectations in relation to educational services were not met, forcing some students to leave the university. ${ }^{10}$

In a study by Barnes, ${ }^{11}$ too, use of SERVQUAL tool among Chinese students showed negative gaps in all the aspects of educational quality.

Now, that the universities in Iran are moving toward qualitative developments rather than quantitative development, it is necessary to carry out such studies in Iran more than ever. In addition, since no such study has been carried out in Tabriz University of Medical Sciences, this study was undertaken to evaluate the quality of educational services by determining the gaps between students' expectations and perceptions in Tabriz University of Medical Sciences in relation to the quality of educational services.

\section{MATERIALS AND METHODS}

In this descriptive/analytical and cross-sectional study, the students studying in Tabriz University of Medical Sciences in 2016, who had studied for at least four semesters, were evaluated. The sample size was estimated at 370 subjects using the Cochrane formula, which increased to 400 subjects by considering an approximate response rate of $90 \%$. Sampling was carried out using the simple random and stratified sampling techniques in terms of the number of students in each faculty.

Data were collected with the use of a two-part questionnaire. The first part consisted of questions on the demographic data of the subjects and the second part consisted of 26 questions on students' perceptions and 26 questions on their expectations in relation to the quality of educational services. This part of the questionnaire was designed based on SERVQUAL tool and by considering the five aspects of the quality of services, including physical and tangible, reliability, responsiveness, empathy, and assurance.

The questions on perceptions of the quality of educational services (the status quo) evaluated what they perceived as the quality of education and the questions on expectations determined their expectations of the quality of educational services (the ideal situation). To reply to the questions on the questionnaire, Likert's 5-point scoring system was used, and the subjects were able to choose one of the following choices for each question: Strongly agree $=5$, agree $=4$, no idea $=3$, disagree $=2$, and strongly disagree $=1$.
In the first stage, after the sampling procedure, the questionnaires were distributed and collected. Then the questionnaires on expectations from a favorable university were distributed among the same subjects and then collected. To determine the gap in quality, the students' scores on the status quo of educational services (their perception of the educational services rendered) were compared with their scores for the favorable quality of educational services (their expectations of the quality of services). A positive score was considered a high quality of the educational services offered relative to the students' expectations and a negative score indicated that the educational services did not satisfy the students' expectations and there were gaps between expectations and the status quo. A zero score indicated the absence of a gap between expectations and the educational quality.

Previous studies have shown the validity of this questionnaire. In addition, the reliability of the questionnaire has been confirmed by Cronbach's alpha at a range of 0.78 to $0.94 .{ }^{1,12}$ However, for better reliability, its content validity was confirmed under the supervision of professors. Furthermore, its reliability was confirmed by calculating Cronbach's alpha at 0.89 in the two fields of expectations and perceptions.

\section{Ethical Approval}

All the ethical and the humanity considerations were considered and performed according to the Helsinki humanity research declaration. The Ethics Committee of the Tabriz University of Medical Sciences approved all the humans' experiments.

Data were analyzed with descriptive statistics (frequencies, means \pm standard deviations) and chi-squared test using Statistical Package for the Social Sciences (SPSS) version 21. Statistical significant was set at $\mathrm{p}<0.05$.

\section{RESULTS}

In this study, 402 students in Tabriz University of Medical Sciences, with the mean age of $19.9 \pm 6$ years, were evaluated; $54 \%$ of the students were males and $46 \%$ were females. Table 1 presents the frequencies of the students in different fields or majors separately.

Table 1: The frequencies (percentages) of students participating in the study separately in each field

\begin{tabular}{ll}
\hline Major or field & Number (\%) \\
\hline Dentistry & $51(12.7)$ \\
Medicine & $49(12.2)$ \\
Pharmaceutics & $45(11.2)$ \\
Paramedical & $54(13.4)$ \\
Rehabilitation & $50(12.4)$ \\
Nutrition and hygiene & $50(12.4)$ \\
Management of therapeutic services & $53(13.2)$ \\
Nursing and midwifery & $50(12.4)$ \\
\hline
\end{tabular}


The results showed that the mean scores of the students' expectations and perceptions of the educational quality were $4.5 \pm 0.33$ and $2.9 \pm 0.7$ respectively, with a mean gap of $-1.5 \pm 0.7$. In other words, based on the students' opinions, the educational quality was less than that expected by the students and did not satisfy them. Table 2 presents the mean scores of expectations, perceptions, and gaps of the quality of educational services separately for each statement on the questionnaire and the different aspects of SERVQUAL model.
As shown in Table 2, in all the aspects of educational quality, there were negative gaps and the services did not meet the students' expectations. In the evaluation of the statements on the questionnaire separately, the greatest and least gaps were reported to the quality of equipment (new equipment and educational materials) and the professional and neat appearance of professors respectively. In addition, the greatest and least gaps were related to responsiveness and assurance. Analysis of variance (ANOVA) showed that the differences were statistically significant $(\mathrm{p}=0.008)$.

Table 2: The mean scores of expectations, perceptions, and gaps of the educational quality separately for each statement on the questionnaire and the aspects of the quality of educational services based on the students' opinions

\begin{tabular}{|c|c|c|c|}
\hline Dimensions of service & Expectations & Perceptions & Gap \\
\hline \multicolumn{4}{|l|}{ Tangible } \\
\hline Neat and professional appearance of the personnel and academic staff members & 4.37 & 3.57 & -0.78 \\
\hline The attractiveness of the atmosphere and physical facilities including classes & 4.46 & 2.57 & -1.88 \\
\hline Efficacy and novelty of equipment and educational materials & 4.6 & 2.49 & -2.1 \\
\hline $\begin{array}{l}\text { The attractiveness of the tools and equipment used by the professors (slides, } \\
\text { books, pamphlets, etc.) }\end{array}$ & 4.48 & 2.98 & -1.49 \\
\hline Total & $4.49 \pm 0.48$ & $2.9 \pm 0.8$ & $-1.58 \pm 0.97$ \\
\hline \multicolumn{4}{|l|}{ Responsiveness } \\
\hline Availability of advisors and consultants when the students need them & 4.47 & 2.7 & -1.69 \\
\hline $\begin{array}{l}\text { Easy access of students to educational managers to express their opinions and } \\
\text { suggestions in relation to educational matters }\end{array}$ & 4.43 & 2.68 & -1.73 \\
\hline Introducing appropriate sources to students for further studies & 4.5 & 3.04 & -1.49 \\
\hline $\begin{array}{l}\text { The possibility of taking students' opinions into account in relation to educational } \\
\text { matters, such as examination timetables }\end{array}$ & 4.43 & 2.63 & -1.79 \\
\hline Total & $4.47 \pm 0.44$ & $2.78 \pm 0.88$ & $-1.68 \pm 0.96$ \\
\hline \multicolumn{4}{|l|}{ Empathy } \\
\hline Respectful behavior of professors toward students & 4.59 & 3.07 & -1.51 \\
\hline Appropriate time of classes & 4.5 & 2.7 & -1.77 \\
\hline Professors' flexibility in special situations that students might encounter & 4.49 & 2.6 & -1.83 \\
\hline $\begin{array}{l}\text { Assigning a proper volume of homework related to lessons (neither too much } \\
\text { nor too little) }\end{array}$ & 4.26 & 2.83 & -1.42 \\
\hline Good behavior of educational personnel toward students & 4.55 & 2.97 & -1.57 \\
\hline Availability of a calm environment within the faculty for students to study in & 4.6 & 3.37 & -1.44 \\
\hline Total & $4.5 \pm 0.39$ & $2.94 \pm 0.77$ & $-1.57 \pm 0.86$ \\
\hline \multicolumn{4}{|l|}{ Reliability } \\
\hline Presentation of lessons in a manner for students to understand & 4.6 & 2.95 & -1.4 \\
\hline Easy access of students to references in the university & 4.55 & 2.84 & -1.7 \\
\hline Acquisition of better grades by students when trying harder & 4.49 & 3.1 & -1.4 \\
\hline Informing the student of the results of their evaluations & 4.37 & 2.75 & -1.61 \\
\hline Registration and preservation of educational records without any mistakes & 4.43 & 3.08 & -1.3 \\
\hline Presentation of lessons in each session in an orderly and coherent manner & 4.5 & 2.96 & -1.53 \\
\hline Fulfilling the responsibilities by the education office personnel on time & 4.38 & 2.94 & -1.43 \\
\hline Total & $4.48 \pm 0.43$ & $2.97 \pm 0.79$ & $-1.53 \pm 0.87$ \\
\hline \multicolumn{4}{|l|}{ Assurance } \\
\hline $\begin{array}{l}\text { Preparing students for their future career by presenting proper practical and } \\
\text { theoretical lessons }\end{array}$ & 4.6 & 2.8 & -1.36 \\
\hline $\begin{array}{l}\text { Allocation of time for answering the students' questions and explaining the lessons } \\
\text { out of class }\end{array}$ & 4.2 & 2.8 & -1.44 \\
\hline Availability of adequate references to increase the students' knowledge & 4.6 & 2.8 & -1.7 \\
\hline Adequate knowledge of professors & 4.6 & 3.4 & -1.19 \\
\hline Discussing and exchanging views about the lessons by professors in classes & 4.5 & 3.18 & -1.36 \\
\hline Total & $4.55 \pm 0.37$ & $3.03 \pm 0.88$ & $-1.5 \pm 0.98$ \\
\hline
\end{tabular}


Evaluation of the Quality of Educational Services of Tabriz University of Medical Sciences based on SERVQUAL Model

Table 3: The mean scores of expectations, perceptions, and quality gaps separately for both genders and for different study fields

\begin{tabular}{llll}
\hline & Expectations & Perceptions & Gap \\
\hline Gender & & & $-1.5 \pm 0.81$ \\
$\quad$ Male students & $4.47 \pm 0.33$ & $2.96 \pm 0.74$ & $-1.65 \pm 0.71$ \\
$\quad$ Female students & $4.56 \pm 0.31$ & $2.9 \pm 0.61$ & $-2.05 \pm 0.43$ \\
Major & & & $-1.91 \pm 0.37$ \\
Paramedical & $4.6 \pm 021$ & $2.58 \pm 0.4$ & $-1.77 \pm 0.31$ \\
Nursing and midwifery & $4.49 \pm 0.13$ & $2.58 \pm 0.35$ & $-1.76 \pm 0.68$ \\
Rehabilitation & $4.36 \pm 0.1$ & $2.59 \pm 0.3$ & $-1.52 \pm 0.67$ \\
Dentistry & $4.7 \pm 0.29$ & $2.93 \pm 0.61$ & $-1.44 \pm 0.92$ \\
Management of therapeutic services & $4.42 \pm 0.16$ & $2.89 \pm 0.63$ & $-1 \pm 0.86$ \\
Medicine & $4.63 \pm 0.36$ & $3.18 \pm 0.81$ & $-0.9 \pm 0.91$ \\
Nutrition and hygiene & $4.39 \pm 0.49$ & $3.34 \pm 0.87$ & $3.48 \pm 0.78$ \\
Pharmaceutics & $4.38 \pm 0.48$ & & \\
\hline
\end{tabular}

As shown in Table 3, there were greater gaps in the quality of services based on female students' opinions compared with male students' opinions, and the female students were dissatisfied with the quality of educational services to a higher rate compared with male students; t-test for independent groups showed that this difference was significant statistically $(\mathrm{p}=0.005)$. To compare the scores of the gaps in the quality of educational services between different faculties ANOVA was used, and the results showed significant differences in the quality of educational services between different faculties based on the opinions of students with the greatest gap score of $-2.05 \pm 0.43$ in the educational quality of paramedical faculty and the least in the pharmaceutics faculty with a mean of $-0.9 \pm 0.91(p=0.0001)$.

\section{DISCUSSION}

The results of this study showed negative gaps in all the aspects of the quality of educational services and the relevant statements on the questionnaire; in other words, based on the students' opinions, the educational services of the university were below the expectations and measures should be adopted to meet the students' expectations.

Different studies in medical universities in Urmia, Hormozgan, ${ }^{1}$ Zahedan, ${ }^{13}$ Shiraz, ${ }_{14}^{14}$ and Shahroud ${ }^{8}$ have shown gaps between the students' expectations and the real situations. In studies by Mukhopadhyay ${ }^{12}$ in India, Barnes ${ }^{11}$ in China, and Tan and Kek ${ }^{15}$ in Singapore, similar results have been achieved. This might indicate that the country's educational system has not been based on the students' demands and expectations and the educational system has not been able to fulfill its commitments and satisfy the students' expectations, necessitating some reforms in the system. Although high and unrealistic expectations of students from their universities might explain these gaps, since the students are the main recipients of these educational services, their expectations should be taken into account.
In addition, in this study, there was a significant difference in the mean gaps in the quality of education between male and female students with greater gaps in the quality based on the female students' opinions compared with male students.

In addition, the gap was the widest based on the opinions of paramedical faculty students among all the other students. The least quality gap was reported by the students in the Faculty of Pharmaceutics.

In other words, the female and male students in the paramedical faculty expressed the least level of satisfaction with the quality of education. In general, it can be pointed out that the quality of a service depends on the opinions of individuals and might have different meanings for different individuals (males and females or students in different fields).

In this study, the greatest negative gap was noted with responsiveness, with the least in assurance, consistent with the results of a study by Nabilou and KhorasaniZavareh $^{9}$ in Urmia University of Medical Sciences. It appears a greater negative gap in responsiveness indicates that the advising and consulting professors are almost unavailable when the students need them. On the contrary, less attention is paid to the students' opinions about educational subjects.

In a study by Aghamolaei and Zare ${ }^{1}$ in Hormozgan University of Medical Sciences, the greatest quality gap was noted in responsiveness, with the least in reliability. After responsiveness, the physical aspect ranked the second in relation to the gap.

Mukhopadhyay ${ }^{12}$ carried out a study in Bengal, India, in 2016. The results showed the greatest gap in the physical aspect.

In a study by Ruby ${ }^{16}$ on the satisfaction of students with the quality of educational services, reliability and assurance exhibited the greatest and least negative gaps in quality respectively; however, in the physical aspect there was a positive quality gap and the students' perceptions of the quality of educational services exceeded their expectations. 
Richard and Adam ${ }^{17}$ showed in a study in the United States that there were negative gaps in assurance and responsiveness.

An evaluation of the results of studies carried out in Iran and in other countries shows gaps in the quality of the majority of the five aspects of services. The results of this study are consistent with the results of some studies carried out in Iran and in other countries, contrary to the results of some other studies. It appears so due to differences in the courses and educational levels, facilities, equipment, the personnel and the academic staff in universities, and also differences in the cultural, social, etc., aspects in different communities. The opinions of the clients about the quality of the educational services and their expectations and perceptions are different. Therefore, the results of this study cannot be extended to other universities. As a result, it is recommended that such studies be carried out in other universities too so that it would be possible to achieve patterns with better adaptability to different universities and use them to improve the quality of education in each university by better and more detailed programming.

\section{CONCLUSION}

The results of this study showed negative gaps in all the aspects of educational quality. However, the existing gaps in all the aspects of the quality of such services can be used as guides for programming and allocation of resources. In this context, the five aspects of educational quality can be categorized into three priority groups for the allocation of resources and the institutes' efforts to eliminate or decrease the quality gaps. Responsiveness and physical aspects can be placed in the highest priority, followed by empathy and reliability in the next priority group, and assurance in the last rank in relation to priority. If such a prioritization is carried out and first the dimensions that have the greatest gaps are addressed, the quality of other aspects too will improve based on the students' opinions, with a decrease in the gaps in the high-priority aspects. Therefore, it is suggested that courses be held for the personnel and the academic staff each year on the effective methods of offering educational services and on how to establish an effective communication with students. In addition, it is important to hold educational workshops for the academic staff members of universities on how to use new educational methods, on counseling skills, and on skills to communicate with students. Furthermore, adequate information should be provided for students and proper programming techniques for classes should be offered to the professors in relation to proper hours for students to visit the consultants and advisors. On the contrary, the managers should allocate definite hours to answer the students' questions and solve their problems. Finally, the constructive opinions of the students should be used in educational programming.

\section{REFERENCES}

1. Aghamolaei $T$, Zare S. Quality gap of educational services in viewpoints of students in Hormozgan University of medical sciences. BMC Med Educ 2008 Jun;8(1):34.

2. Bahadori $M$, Sadeghifar J, Nejati $M$, Hamouzadeh $P$, Hakimzadeh M. Assessing quality of educational service by the SERVQUAL model: viewpoints of paramedical students at Tehran university of medical science. Tech Technol Educ Manage (TTEM) 2011 Jan;6(4):1058-1065.

3. Parasuraman A, Zeithaml VA, Berry LL. Servqual: A multipleitem scale for measuring consumer perc. Journal of retailing 1988;64(1):12.

4. Kumar A, Dash MK. Constructing a measurement in service quality for Indian banks: structural equation modeling approach. J Internet Bank Commer 2013 Apr;18(1):1-6.

5. Altuntas S, Dereli T, Yilmaz MK. Multi-criteria decision making methods based weighted SERVQUAL scales to measure perceived service quality in hospitals: a case study from Turkey. Total Qual Manage Bus Excell 2012 Dec;23(11-12): 1379-1395.

6. Vaz A, Mansori S. Malaysian private education quality: application of SERVQUAL model. Int Educ Stud 2013 Mar;6(4):164-170.

7. Butt MM, de Run EC. Private healthcare quality: applying a SERVQUAL model. Int J Health Care Qual Assur 2010 Sep;23(7):658-673.

8. Rajabi M, Rajabi AA. Educational service quality assessment from a student point of view according to the SERVQUAL model. Int J Sport Stud 2014;4(2):146-150.

9. Nabilou B, Khorasani-Zavareh D. The bridge between real and ideal: students' perception on quality gap in reality and their educational expectations. Iran Red Crescent Med J 2014 Sep;16(9):e14254.

10. Slade P, Harker M, Harker D. Why do they leave, why do they stay. Perceptions of service quality at a New Jersey University Visionary Marketing for the 21st century: facing the challenge. ANZMAC; 2000. p. 1197-1200.

11. Barnes BR. Analyzing service quality: the case of postgraduate Chinese students. Total Qual Manage Bus Excell 2007 May;18(3):313-331.

12. Mukhopadhyay DK. Students' perception of quality of medical education in a medical college in West Bengal, India. Indian J Public Health 2016 Jan-Mar;60(1):4-9.

13. Kebriaei A, Akbari F. Quality gap of educational services at Zahedan University of Medical Sciences, Iran. Bangladesh Med Res Counc Bull 2008 Dec;34(3):76-80.

14. Rahim Khanli M, Daneshmandi H, Choobineh A. The students' viewpoint on the quality gap in educational services. J Adv Med Educ Prof 2014 Jul;2(3):114-119.

15. Tan KC, Kek SW. Service quality in higher education using an enhanced SERVQUAL approach. Qual High Educ 2004 Apr;10(1):17-24.

16. Ruby CA. Assessing satisfaction with selected student services using SERVQUAL, a market-driven model of service quality. J Stud Aff Res Pract 1998 Jun;35(4):331-341.

17. Richard E, Adams J. Assessing college student perceptions of instructor customer service to student's questionnaire: assessment in higher education. J Assess Eval High Educ 2006 Oct;31(5):535-549. 